\title{
Synthesis of Doped and non-Doped Nano MgO Ceramic Membranes
}

\author{
Shiraz Labib
}

\begin{abstract}
Nuclear Chemistry Department, Hot Laboratories Center, Atomic Energy Authority, Cairo,Egypt,Email:dr_sh_labib@yahoo.com.
\end{abstract}

\begin{abstract}
Doped and non-doped $\mathrm{MgO}$ coated thin films on alumina substrates were prepared using a chelating sol-gel method under controlled conditions to prepare nanomaterials with unprecedented properties. The effect of doping of $\mathrm{ZnO}$ on thermal, surface and structural properties was investigated using DTA-TG, BET and XRD respectively. Also microstructural studies and coating thickness measurements of $\mathrm{MgO}$ thin film were conducted using SEM. An increase in the thermal stability of $\mathrm{MgO}$ with increasing $\mathrm{ZnO}$ doping percent was observed. The increase of $\mathrm{ZnO}$ doping percent showed a marked decrease in the average particle size of $\mathrm{MgO}$ powder as a result of the replacement of some $\mathrm{Mg}^{2+}$ by $\mathrm{Zn}^{2+}$ which has similar ionic radius as $\mathrm{Mg}^{2+}$. This decrease in particle size of $\mathrm{MgO}$ was also related to the decrease of the degree of $\mathrm{MgO}$ crystalinity. The increase of $\mathrm{ZnO}$ doping also showed a marked decrease in coating thickness values of the prepared membranes. This decrease was related to the mechanism of $\mathrm{ZnO}$ doping into a $\mathrm{MgO}$ crystal lattice.
\end{abstract}

Keywords: $\mathrm{MgO}$; $\mathrm{MgO}-\mathrm{ZnO}$; polymeric sol-gel; doping mechanism; nano properties; thin films.

$$
\text { تحضير أغشية سيراميكية مطعمة وغير مطعمة من نانو أكسيد الماغنيسيوم }
$$

$$
\text { شبيراز لبيب }
$$

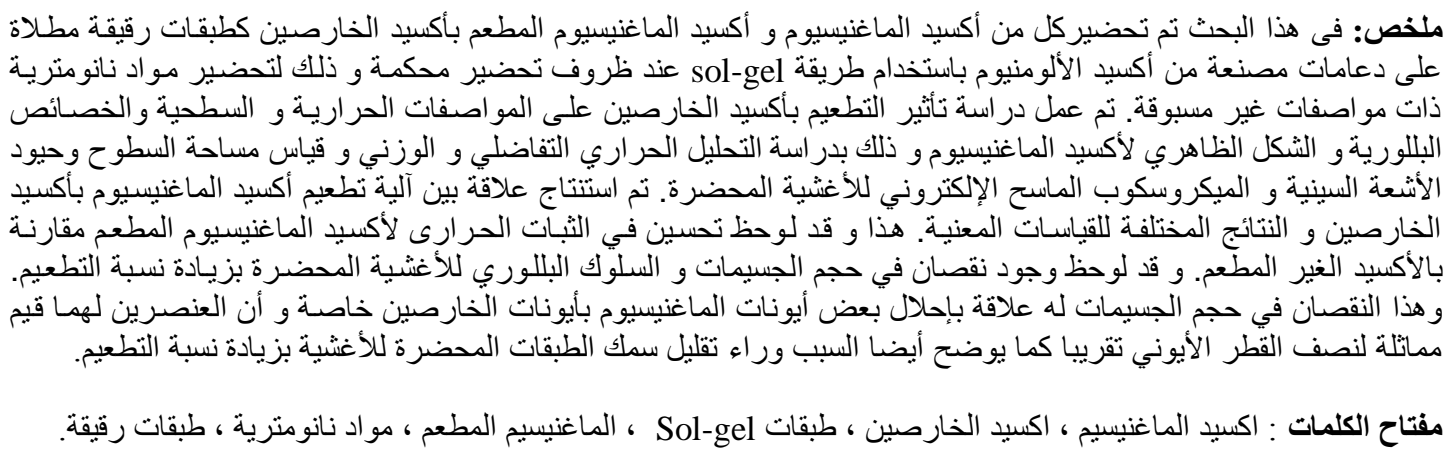

\section{Introduction}

$\mathbf{M}$ $\mathrm{gO}$ is a highly ionic crystalline solid, which crystallizes into a cubic rock salt structure. It is characterized by a large band gap (7.8 eV), high thermal conductivity and stability (Raj et al., 2007). It has extensive applications in the area of toxic waste remediation, refractory, paint and superconductor products. It also shows excellent adsorption properties in enhanced surface areas and intrinsically higher surface reactivity (Niu et al., 2006). Due to its superior electronic properties, it can be used as a substrate for high temperature superconductor film deposition. It has a wide application in microwave devices (Raj et al., 2007). MgO thin films are of scientific and technological importance due to their applications in optical and electronic devices, in catalytic reactions, as protective coatings on metals and in gas sensors (Raj et al., 2007). Therefore, $\mathrm{MgO}$ is considered an important applied and economical material. Nano MgO ceramic membranes are prepared by a sol-gel process that offers enhanced homogeneity and better control for the size, the shape and the degree of agglomeration of the resulting nanocrystals, as well as simple compositional control and low processing temperature (Maensiri et al., 2007; Iyer et al., 2009; Desai et al., 2007; Caruntu, 2006; Cernea, 2005; 
Willard et al., 2004). A better control of precursor reactivity may be achieved through the addition of chelating agents such as B-diketones, carboxylic acids or other complex ligands (Cernea, 2005; Sanchez et al., 1988).

This paper deals with the preparation of doped and non-doped nano $\mathrm{MgO}$ membranes using a polymeric sol-gel method that offers the possibility of controlling the synthesis of thin film hierarchical internal structure (Crisan et al. 2000). Doping $\mathrm{MgO}$ with $\mathrm{ZnO}$ is studied in order to create doped nanocrystals and nanostructures with unprecedented properties (Yang et al., 2010). The effect of $\mathrm{ZnO}$ doping on thermal, surface and structural properties is studied. Also microstructural studies and coating thickness measurements of $\mathrm{MgO}$ thin film are conducted. The relationship between the mechanism of $\mathrm{ZnO}$ doping into a $\mathrm{MgO}$ crystal lattice and the properties studied is discussed.

\section{Experimental}

\subsection{Substrate preparation}

Disk alumina substrates of thickness $(0.1 \mathrm{~cm})$, diameter $(10 \mathrm{~cm})$, pore size distribution $(0.1 \mu \mathrm{m})$, and porosity $(18.42 \mathrm{Vol} . \%)(\mathrm{Labib}, 2006)$ were used for doped and non-doped $\mathrm{MgO}$ coating thin films.

These substrates were synthesized by a polymeric sol-gel process using aluminium tri-second butylate $(99.9 \%$ Merck, Germany), distilled water, isopropyl alcohol (99.8\% Scharlau, Spain) and glacial acetic acid (98\% Merck, Germany). The precursors used were of A.R. grade.

Glacial acetic acid $(2 \mathrm{~mol})$, as a chelating agent, was added to the alcoholic solution of aluminium tri-second butylate having the molar ratio (isopropyl alcohol/aluminium tri-second butylate: 5:1 respectively). This solution was stirred for ten minutes, then it was exposed to a controlled rate of hydrolysis with a diluted solution of isopropyl alcohol having the molar ratio (isopropyl alcohol/distilled $\mathrm{H}_{2} \mathrm{O}:$ 5:0.5 respectively). The prepared polymeric sol was stirred for ten minutes and then aged at room temperature for $48 \mathrm{~h}$. The aged polymeric sol was dried at $120^{\circ} \mathrm{C}$ for $1 \mathrm{~h}$, calcined at $500{ }^{\circ} \mathrm{C}$ for $1 \mathrm{~h}$, ground for $15 \mathrm{~min}$, pressed uniaxially at $12 \mathrm{k} . \mathrm{N}$ using (poly vinyl alcohol) as a binder and then sintered at $1100{ }^{\circ} \mathrm{C}$ for $1 \mathrm{~h}$ (Labib, 2006).

\subsection{Membrane preparation}

Doped and non-doped $\mathrm{MgO}$ ceramic membranes were initially prepared using magnesium nitrate hexahydrate [99\% Winlab, England], zinc nitrate hexahydrate [99\% Merck, Germany], isopropyl alcohol [99.8\% Scharlau, Spain], acetylacetone $[\geq 99 \%$ Merck, Germany] and distilled water. All the reagents used were of A.R. grade. The composition of the prepared samples is shown in Table 1.

Table 1. Composition of the prepared samples.

\begin{tabular}{ccc}
\hline Sample & $\mathrm{MgO} \%$ & $\mathrm{ZnO} \%$ \\
\hline M100 & 100 & 00 \\
M99 & 99 & 01 \\
M95 & 95 & 05 \\
M90 & 90 & 10 \\
\hline
\end{tabular}

Polymeric magnesium oxide sol was prepared by drop-wise addition of an alcoholic mixture of isopropyl alcohol $(5.0 \mathrm{~mol})$ and distilled water $(1.0 \mathrm{~mol})$ to the stirred alcoholic solution of magnesium nitrate hexahydrate and acetyl acetone having the molar ratio (isopropyl alcohol /magnesium nitrate /acetyl acetone: 10:0.8:1.6 respectively).

The different doped $\mathrm{MgO}-\mathrm{ZnO}$ sols were prepared by adding 1, 5 and 10\% of zinc nitrate hexahydrate to each of the alcoholic solutions of 99, 95 and $90 \%$ of magnesium nitrate hexahydrate, followed by adding acetyl acetone. The mixed polymeric sols were prepared by drop-wise hydrolysis with the alcoholic mixture of isopropyl alcohol and distilled water. The different prepared polymeric sols were stirred vigorously for $20 \mathrm{~min}$.

The dip coat process was performed at room temperature by immersing alumina substrates into the different polymeric sols for $2 \mathrm{~h}$ (Peters et al., 2005), (immersion and withdrawal rate: $0.5 \mathrm{~mm} \mathrm{~s}^{-1}$ ). After dip coating, the different ceramic membranes were left overnight to be dried at room temperature. The different prepared membranes and the unsupported membranes were dried at $200{ }^{\circ} \mathrm{C}$ for $1 \mathrm{~h}$ with a heating rate of $3{ }^{\circ} \mathrm{C} \mathrm{min}^{-1}$. The process of dipping, withdrawing and drying was repeated 6 times to obtain suitable coating thicknesses (Sekulic et al., 2006) and then the membranes were sintered at 400 and $600{ }^{\circ} \mathrm{C}$ for $6 \mathrm{~h}$ with a heating rate of $3{ }^{\circ} \mathrm{C} \min ^{-1}$.

\subsection{Membrane characterization}

The thermal degradation behaviors of the unsupported membranes were studied using differential thermal analysis (DTA) and thermogravimetric (TG) analysis (Shimadzu 60, Japan). DTA/TG studies were performed by heating the sample from room temperature to $400{ }^{\circ} \mathrm{C}$ in an air atmosphere with a heating rate of $3{ }^{\circ} \mathrm{C} \mathrm{min}{ }^{-1}$. Specific surface area measurements were taken, applying the Brunauer-Emmet-Teller (BET) method, using (Nova 3200 Series, 
USA). Prior to the analysis, the different samples were evacuated at $300{ }^{\circ} \mathrm{C}$ for $2 \mathrm{~h}$. Particle size values of the unsupported membranes were calculated from:

$$
\mathrm{d}_{\mathrm{BET}}=6 / \mathrm{SSA}_{\mathrm{BET}} \cdot \rho_{\text {sample }}
$$

where, $\rho_{\text {sample }}$ is the density of the samples used (Mikhail and Robens, 1975), $\rho_{\text {sample }}$ was calculated from the density of $\mathrm{MgO}(\rho \mathrm{MgO})=3.58 \times 10^{3} \mathrm{~kg} / \mathrm{m}^{3}$ and the density of $\mathrm{ZnO}(\rho \mathrm{ZnO})=5.61 \times 10^{3} \mathrm{~kg} / \mathrm{m}^{3}$ taking into consideration the appropriate amount of both components (Samerjai et al., 2009). The crystal structures of the different unsupported membranes were identified using X-ray diffraction (XRD) (Philips X'pert multi-purpose diffractometer, USA). A copper-tube X-ray tube operating at $40 \mathrm{kV}$ and $30 \mathrm{~mA}$ was used, and the wavelength $\mathrm{K}_{\alpha 1}$ used was 1.54056 $\mathrm{A}^{0}$. The scan was performed over the range $2 \theta$ (40-70). The identification of the crystalline phases present was done using the JCPDS database cards. The microstructures and coating thicknesses of the prepared membranes were studied using a scanning electron microscopy (SEM) (JEOL JSM-5600, Japan). Prior to SEM analysis, the samples were sputtered with a thin layer of gold using JEOL Fine Coat (JFC-1500 Ion Sputtering Device, Japan).

\section{Results and discussion}

\subsection{Unsupported membranes}

\subsubsection{Differential thermal analysis-thermogravimetric analysis (DTA-TG)}

Thermal properties of the unsupported membranes were investigated using DTA/TG analysis and the corresponding curves are shown in Figure 1. Owing to the low heating rate used $\left(3{ }^{\circ} \mathrm{C} \mathrm{min}{ }^{-1}\right)$, the samples were heated only to $400{ }^{\circ} \mathrm{C}$. TG curve for the sample M100 shows two weight losses at $\mathrm{T}<300{ }^{\circ} \mathrm{C}$. The gradual mass loss below $300{ }^{\circ} \mathrm{C}$ could be assigned to the evaporation and the elimination of the bonded water, residual organic solvents as well as to the burning of nitrate groups from the metal nitrate precursor. This result was correlated to the two endothermic peaks of the DTA curve at $\mathrm{T}<100{ }^{\circ} \mathrm{C}$ ( $\mathrm{Li}$ et al., 2008; Anas et al., 2010). The third distinct weight loss $\sim 37.83 \%$ at 100$400{ }^{\circ} \mathrm{C}$ was due to the crystallization of $\mathrm{Mg}(\mathrm{OH})_{2}$ to cubic $\mathrm{MgO}$ as indicated from the weight loss value (37.83\%).

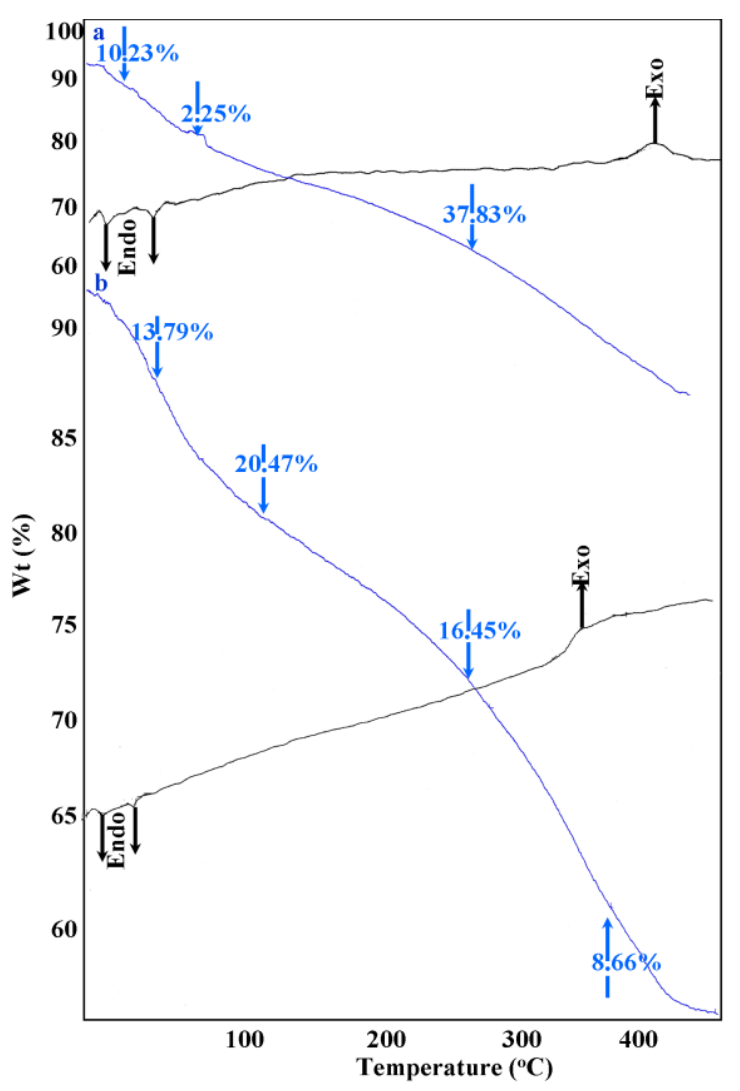

Figure 1. DTA-TG analysis for (a) M100 and (b) M90 membranes in air with a heating rate of $3{ }^{\circ} \mathrm{C} / \mathrm{min}$.

The theoretical weight loss for $\mathrm{Mg}(\mathrm{OH})_{2}$ transformation to $\mathrm{MgO}$ is (30.8\%) (Niu et al., 2006). The exothermic peaks at $400{ }^{\circ} \mathrm{C}$ in the DTA curve demonstrated the occurrence of the reaction (Li et al., 2008). On the other hand, the TG curve for M90 shows four distinct weight loss regions at temperatures $\left(20-400{ }^{\circ} \mathrm{C}\right)$ : two weight losses $\sim 13.8$ and 
$20.4 \%$ from 20 to $250{ }^{\circ} \mathrm{C}$ corresponding to the combined evaporation of bonded water, residual organic solvents and the nitrate groups from both magnesium nitrate and zinc nitrate. This explained the increase in weight loss percent with respect to the pure material. The two weight losses $\sim 16.5$ and $8.7 \%$ at $250-400{ }^{\circ} \mathrm{C}$ correspond to the transformation to $\mathrm{MgO}$ and $\mathrm{ZnO}$ respectively taking in mind the stoichiometric ratio of the metal precursor used. An important feature which was observed was the shift of weight loss to higher temperature with respect to the case of pure material. This result indicated the role of dopant $(\mathrm{ZnO})$ in increasing the thermal stability of the $\mathrm{MgO}$ phase (Han et al., 2007). Also, the presence of two weight losses at $250-400{ }^{\circ} \mathrm{C}$ confirmed the presence of two phases: cubic $\mathrm{MgO}$ and hexagonal $\mathrm{ZnO}$ wurtzite structures.

\subsubsection{Specific surface area measurements (SSA)}

Table 2 shows the specific surface area values of the unsupported membranes thermally treated at $600{ }^{\circ} \mathrm{C}$ for $6 \mathrm{~h}$. A marked increase in specific surface area values was observed with increasing $\mathrm{ZnO}$ doping percent. This increase was accompanied by a decrease in particle size as shown in Table 2. The decrease in particle size means a decrease in the crystalline behavior of the cubic $\mathrm{MgO}$ by incorporating $\mathrm{ZnO}$. This result was explained as follows: since the ionic radius of $\mathrm{Zn}^{2+}(0.083) \mathrm{nm}$ is similar to that of $\mathrm{Mg}^{2+}(0.078) \mathrm{nm}$, the position of $\mathrm{Mg}^{2+}$ can be occupied by $\mathrm{Zn}^{2+}\left(\mathrm{Huang}^{2}\right.$ et al., 2008; Saraiva et al., 2010). $\mathrm{MgO}$ structure is similar to the well-known $\mathrm{NaCl}$ structure. The $\mathrm{O}^{2-}$ anions are in a cubic closest packing and the $\mathrm{Mg}^{2+}$ cations fill all the octahedral sites (Saraiva et al., 2010). The increase in doping percent of $\mathrm{ZnO}$ indicated that the octahedral positions occupied by $\mathrm{Mg}^{2+}$ ions were replaced by $\mathrm{Zn}^{2+}$ ions and when the doping percent reached $50 \%$ the structure became unstable and a disappearance of $\mathrm{MgO}$ structure was observed (Saraiva et al., 2010). In general, the $\mathrm{MgO}$ structure was determined under thermodynamic conditions, the increase of doping percent can decrease the mobility of adatoms ( $\mathrm{ZnO}$ atoms) within the structure. So, the structure became kinetically not thermodynamically determined (Saraiva et al., 2010). This result was confirmed by the increase in the $\mathrm{MgO}$ peak broadness given in XRD results.

Table 2. Specific surface area and particle size values of the unsupported membranes thermally treated at $600{ }^{\circ} \mathrm{C}$ for $6 \mathrm{~h}$.

\begin{tabular}{ccc}
\hline Sample & Specific Surface Area $(\mathrm{SSA})\left(\mathrm{m}^{2} / \mathrm{g}\right)$ & $\begin{array}{c}\text { Particle Size } \\
\mathrm{d}_{\text {BET }}(\mathrm{nm})\end{array}$ \\
\hline M100 & 26.56 & 63.0 \\
M99 & 74.37 & 22.4 \\
M95 & 106.70 & 15.0 \\
M90 & 121.54 & 13.0 \\
\hline
\end{tabular}

\subsubsection{X-Ray diffraction analysis (XRD)}

Figure 2 shows the XRD patterns of doped and non-doped $\mathrm{MgO}$ powder thermally treated at $600{ }^{\circ} \mathrm{C}$ for $6 \mathrm{~h}$. The characteristic peak of pure $\mathrm{MgO}$ (200) was presented at $2 \theta \sim 43$ degrees as indicated from (JCPDS-card N0 45-0946). The development of $\mathrm{ZnO}$ peak (103) at $2 \theta \sim 62$ degree (JCPDS-card N0 36-1451) was observed with increasing ZnO doping percent. A marked increase in the peak broadness of $\mathrm{MgO}$, as marked by the arrow, was observed which confirms the decrease in the particle size and the crystallinity of $\mathrm{MgO}$ with adding $\mathrm{ZnO}$, as given previously. Two important features were observed:

i- $\quad$ The increase of $\mathrm{MgO}$ peak broadness and its shift to a higher angle with increasing $\mathrm{ZnO}$ doping percent. This shift was due to the variation of the lattice parameters confirming that $\mathrm{ZnO}$ was alloyed with $\mathrm{MgO}$ forming a $\mathrm{Mg}(\mathrm{Zn}) \mathrm{O}$ solid solution. This trend was known as Vergard's law which states that the lattice parameters depend on the composition (Saraiva et al. 2010). From this behavior, it was concluded that $\mathrm{Mg}(\mathrm{M}) \mathrm{O}$ systems can be treated as solid solutions (Saraiva et al., 2010). This means that the replacement of $\mathrm{Mg}$ by a cation with smaller radius was accompanied by a decrease in the lattice parameter and the opposite was noticed with a replacement by a larger cation (Saraiva et al., 2010).

ii- The development and the intensity increase of $\mathrm{ZnO}$ peak (103) with increasing the doping percent indicated the presence of $\mathrm{ZnO}$ as a secondary phase. This result was also confirmed from TG results. So, not all $\mathrm{ZnO}$ was alloyed with $\mathrm{MgO}$. 


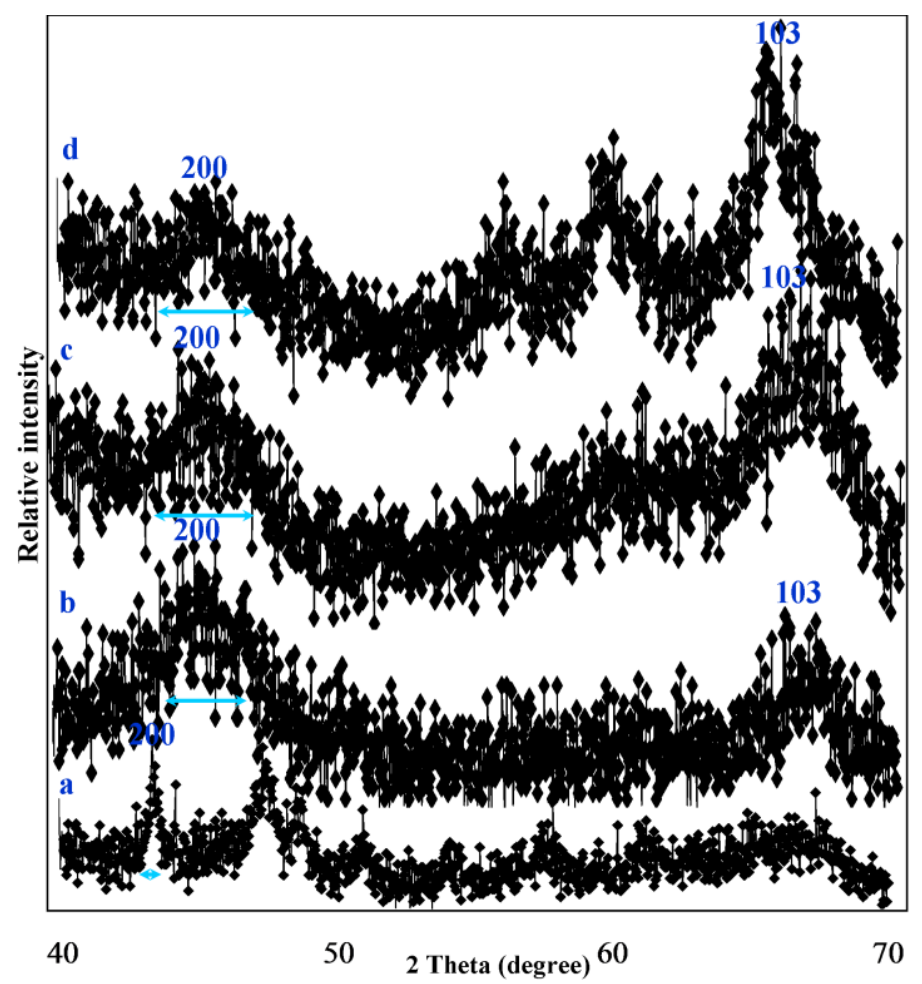

Figure 2. XRD patterns of doped and non-doped $\mathrm{MgO}$ membranes thermally treated at $600^{\circ} \mathrm{C}$ for $6 \mathrm{~h}$. (a) $\mathrm{M} 100$, (b) M99, (c) M95 and (d) M90.

\subsection{Supported membranes}

\subsubsection{Scanning electron microscopy (SEM)}

Figures 3 (a-d) show the SEM, at a magnification power of $8000 \mathrm{x}$, of doped and non-doped MgO thermally treated at $600^{\circ} \mathrm{C}$ for $6 \mathrm{~h}$. A dense film of nanoparticles $(200 \mathrm{~nm})$ was shown in M100. The aggregated nanoparticles were in fact formed from tiny nanocrystallites within the size range of a few $\mathrm{nm}$. The increase in the doping percent of $\mathrm{MgO}$ film with $\mathrm{ZnO}$ shows the development of a porous structure with slight variation in the average particle size. This decrease in structure density with increasing the doping percent can be attributed to the low mobility of the adatoms on the surface of the $\mathrm{MgO}$ films (Park et al., 2005). The decrease in adatom mobility on the $\mathrm{MgO}$ surface leads to the decrease in $\mathrm{MgO}$ (200) orientation, i.e. the decrease of the degree of crystallinity (Park et al., 2005). This result confirmed the result obtained in the SSA and XRD results. The adatoms acted as a grain growth inhibitor and influenced the grain growth kinetics either by pinning grain boundary or by changing the thermodynamic factors such as surface and grain boundary energies respectively (Suzuki et al., 2002). The energy necessary for the movement of $\mathrm{MgO}$ grain boundary increased and the driving force for the grain boundary migration decreased (He et al., 2002) leading to an inhibition of the grain growth. Similar behavior was reported in $\mathrm{MgO}-$ doped $_{\mathrm{Al}_{2} \mathrm{O}_{3}}$ (Suzuki et al., 2002). The reduction in the spread of dihedral angles leading to a homogeneous microstructure was observed because of the presence of dopants (Suzuki et al., 2002).

\subsubsection{Coating thickness}

Coating thickness measurements were done to give a detailed explanation of the kinetic role of $\mathrm{ZnO}$ incorporation into the $\mathrm{MgO}$ system, the mechanism of the film formation and the limit mobility of $\mathrm{ZnO}$ into $\mathrm{MgO}$ crystal lattice. Coating thickness measurements were calculated for the prepared membranes thermally treated at 200 , 400 and $600{ }^{\circ} \mathrm{C}$ using cross SEM investigations.

Figure 4 shows the plot of coating thickness values for the different prepared membranes versus thermal temperatures. The decrease of coating thickness layer with increasing temperature was due to the release of organic by-products and the crystalline formation of the final product, leading to a uniform coated film over the substrate. 

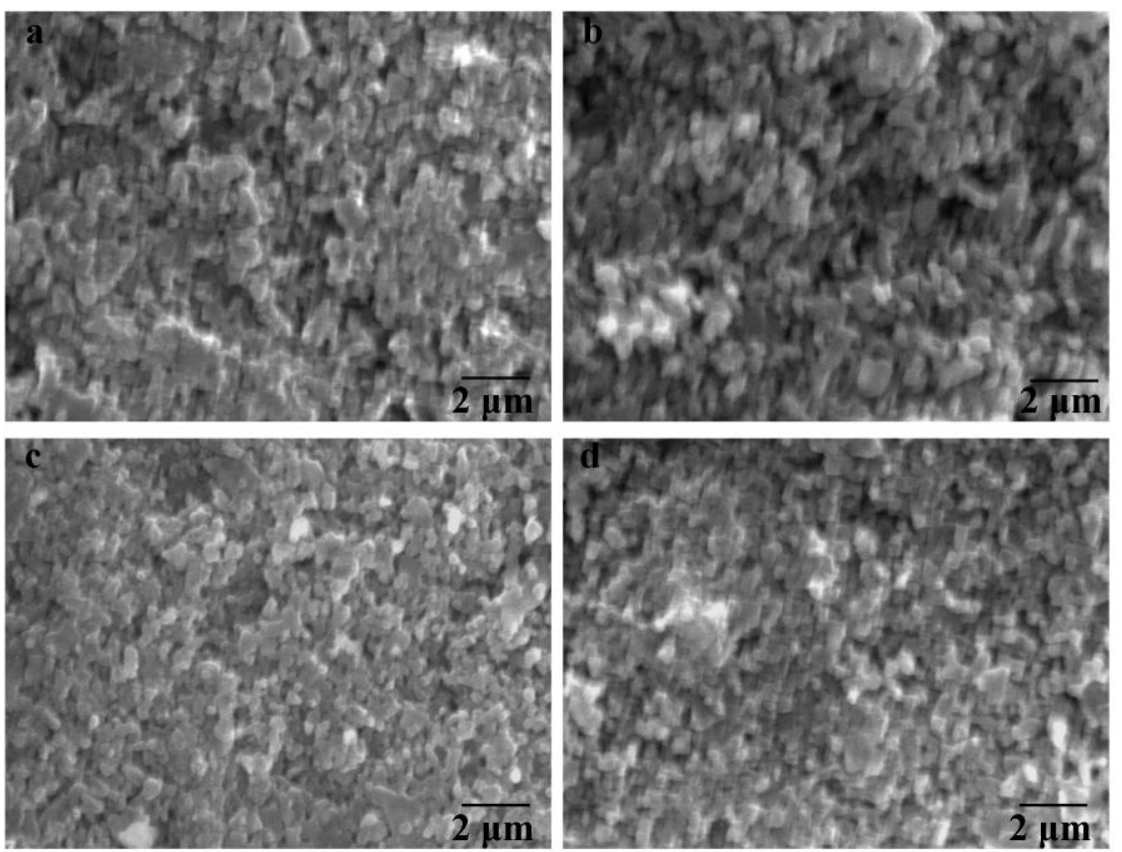

Figure 3. SEM of doped and non-doped $\mathrm{MgO}$ membranes thermally treated at $600^{\circ} \mathrm{C}$ for $6 \mathrm{~h}$. (a) M100, (b) M99, (c) M95 and (d) M90.

The marked decrease of coating thickness values of the prepared thin films were observed with increasing $\mathrm{ZnO}$ doping percent. This behavior was interpreted as follows:

The thickness per deposited layer was dependent on several parameters: the concentration of the precursors, the sol viscosity and the density of the deposited film (Liebrecht, 2006). In a (MgO-ZnO) system, the mobility of the adatoms is more dependent on the film thickness than the other parameters (Guillén and Herrero, 2010). A direct correlation coexists between the mobility increase and both the coating layer thickness and grain size increase (Guillén and Herrero, 2010). On the other hand, the decrease in mobility occurs as a result of the strong interfacial interaction between the deposited film and the substrate leading to the decrease in coating thickness value (Park et al., 2005). It is certain that the adatomic mobility was an important factor affecting the coating thickness as well as the microstructure of the deposited films.

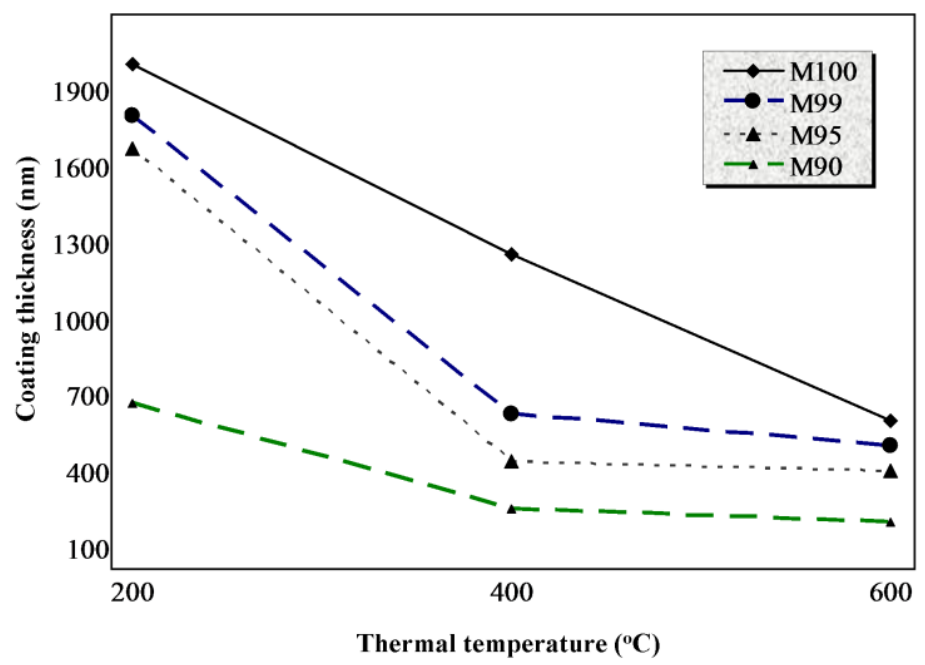

Figure 4. Coating thickness values for doped and non-doped $\mathrm{MgO}$ membranes at different thermal temperatures.

\section{Conclusion}

Doped and undoped $\mathrm{MgO}$ membranes were prepared using a chelating sol-gel process. $\mathrm{ZnO}$ was chosen as a dopant to $\mathrm{MgO}$ in different proportions. The addition of $\mathrm{ZnO}$ to $\mathrm{MgO}$ increased the thermal stability of $\mathrm{MgO}$, as 


\section{SYNTHESIS OF DOPED AND NON-DOPED NANO MgO CERAMIC MEMBRANES}

investigated from DTA-TG results. The marked increase in specific surface area and decrease in particle size values, with increasing doping percent, was due to the decrease of the adatom mobility within the structure when increasing the percent of $\mathrm{Zn}^{2+}$ replacing $\mathrm{Mg}^{2+}$ ions. The increase of $\mathrm{MgO}$ peak broadness with increasing doping percent confirms the BET results. The decrease of adatom mobility affected the microstructure of the obtained films by increasing the porous structure of the obtained films, as shown in SEM investigations, and decreasing the coating thickness values. This was attributed to the strong interfacial interaction created between the deposited film and the substrate as a result of the decrease in adatom mobility. Therefore, the mechanism of increasing the percent of $\mathrm{Zn}^{2+}$ replacing $\mathrm{Mg}^{2+}$ ions played an important role in obtaining nano-coated thin film membranes. The aim of this paper was to understand the true role of doping $\mathrm{ZnO}$ into $\mathrm{MgO}$ matrix because this system is very important and opens the key of knowing the link between the mechanism of doping and the resultant properties. As concluded, the above results are compatible together leading to an improvement in $\mathrm{MgO}$ thin film microstructure with increasing $\mathrm{ZnO}$ doping percent and the field allows for other systems that have similar trends to be studied and applied.

\section{References}

ANAS, SH., MUKUNDAN, P., SANOJ, A.M., MANGALARAJA, V.R. and ANANTHAKUMAR, S. 2010. Synthesis of $\mathrm{ZnO}$ Based nanopowders via a Non-hydrolytic Sol-gel Technique and their Densification Behaviour and Varistor Properties. Process. and Appl. Ceram. 4: 7-14.

CARUNTU, D. 2006. Nanocrystalline Transition metal Ferrites: Synthesis, Characterization and Functionalization. Ph.D. Thesis, University of New Orleans, Louisiana, USA.

CERNEA, M. 2005. Sol-gel Synthesis and Characterization of $\mathrm{BaTiO}_{3}$ Powders. J. Optoelectronics and Advanced Materials 7: 3015-3022.

CRISAN, M., JITIANU, A., CRISAN, D., BALASOIU, M., DRAGAN, N. and ZAHARESCU M. 2000. Sol-Gel Monocomponent Nano-sized Oxide Powders. J. Optoelectronics and Advanced Materials 2: 339-342.

DESAI, R., MEHTA, R.V., UPADHYAY, R.V., GUPTA, A., PRANEET, A. and RAO, K.V. 2007. Bulk Magnetic Properties of Cadmium Ferrite in Nano Regim. Bull. Mat. Sci. 30: 197-203.

GUILLÉN, C. and HERRERO, J. 2010. Optical, Electrical and Structural Characteristics of Al:ZnO Thin Films with Various Thicknesses Deposited by DC Sputtering at Room Temperature and Annealed in Air or Vacuum. Vacuum 84: 924-929.

HAN, Z-D., DIAO, CH., DONG, L. and ZHANG, X. 2007. Thermal Stability and Combustion Behaviors of LLDP/silica Nanocomposites. $16^{\text {th }}$ International Conference on Composite Materials, 8-13 July 2007, Kyoto, Japan.

HE, CH., YU, Y., HU, X. and LARBOT, A. 2002. Influence of Silver Doping on the Photocatalytic Activity of Titania Films. App. Surface Sci. 200: 239-247.

HUANG, CH-L., HOU, J. L., PAN, CH-L., HUANG, CH-Y., PENG, CH-W., WEI, CH-H. and HUANG, Y-H. 2008. Effect of $\mathrm{ZnO}$ Additive on Sintering Behavior and Microwave Dielectric Properties of $0.95 \mathrm{MgTiO}_{3}-0.05 \mathrm{CaTiO}_{3}$ Ceramics. J. Alloys and Compounds 450: 359-363.

IYER, R., DESAI, R. and UPADHYAY, R.V. 2009. Low Temperature Synthesis of Nanosized $\mathrm{Mn}_{1-\mathrm{x}} \mathrm{Cd}_{\mathrm{x}} \mathrm{Fe}_{2} \mathrm{O}_{4}$. Indian J. Pure and Applied Physics 47: 180-185.

LABIB, SH. 2006. Preparation, Characterization and Formulation of Nano-ceramic Materials to be used for the Separation of some Heavy Metals. Ph.D. Thesis, Ain Shams Uni., Egypt.

LI, M., XU, M., LIANG, H., LI, X. and XU, T. 2008. Preparation and Dielectric Properties of Mn-doped $\mathrm{Ba}_{0.6} \mathrm{Sr}_{0.4} \mathrm{TiO}_{3}-\mathrm{MgTiO}_{3}$ Composite Ceramics. Acta Physico-Chimica Sinica 24: 1405-1410.

LIEBRECHT, L.J.H. 2006. Sol-Gel Derived Barium Titanate thin Films. M.Sc. Thesis, Uni. of Twente, The Netherlands.

MAENSIRI, S., MASINGBOON, CH., BOONCHOM, B. and SERAPHIN, S. 2007. A Simple Route to Synthesize Nickel Ferrite $\left(\mathrm{NiFe}_{2} \mathrm{O}_{4}\right)$ Nanoparticles using egg white. Scripta Materialia 56: 797-800.

MIKHAIL, R.SH., ROBENS, E. 1975. Microstructure and Thermal Analysis of Solid Surfaces. John Wiley \& Sons. Chichester, New York, Brisbane, Toronto, Singapore.

NIU, H-X., YANG, Q., YU, F., TANG, K-B. and ZHOU, W. 2006. Simple Synthesis of Single-Crystalline Nanoplates of Magnesium Oxide. Chin. J. Chem. Phys. 19: 438-442.

PARK, S.Y., LEE, M.J., KIM, H.J., MOON, S.H., KIM, S.G. and KIM, J.K. 2005. Relationship between the Microstructure and the Discharge Characteristics of $\mathrm{MgO}$ Protecting Layer in Alternating Current Plasma Display Panels. J. Vac. Sci. Technol. A. 23: 1162-1166.

PETERS, T.A., FONTALVO, J., VORSTMAN, M.A.G., BENES, N.E., VAN DAM, R.A., VROON, Z.A.E.P., VAN SOEST-VERCAMMEN, E.L.J. and KEURENTJES, J.T.F. 2005. Hollow Fibre Microporous Silica Membranes for Gas Separation and Pervaporation. Synthesis, Performance and Stability. J. Memb. Sci. 248: 73-80.

RAJ, A.M.E., NEHRU, L.C., JAYACHANDRAN, M. and SANJEEVIRAJA, C. 2007. Spray Pyrolysis Deposition and Characterization of Highly (100) Oriented Magnesium Oxide thin Films. Cryst. Res. Technol. 42: 867-875.

SAMERJAI, TH., LIEWHIRAN, CH. and PHANICHPHANT, S. 2009. Characterization of $\mathrm{ZnO} / \mathrm{MgO}$ Nanocomposites Synthesized by Flame Spray Pyrolysis. J. Microscopy Soc. Thailand 23: 87-90. 
SANCHEZ, C., LIVAGE, J., HENRY, M. and BABONNEAU, F. 1988. Chemical Modification of Alkoxide Precursors. J. Non-Crystalline Solids 100: 65-76.

SARAIVA, M., GEORGIEVA, V., MAHIEU, S., AEKEN, K.V., BOGAERTS, A. and DEPLA, D. 2010. Compositional Effects on the Growth of $\mathrm{Mg}(\mathrm{M}) \mathrm{O}$ films. J. Appl. Phys. 107: 1-10

SEKULIC, J., LUITEN, M.W.J., ELSHOF, J.E.T., BENES, N.E. and KEIZER, K. 2006. Microporous silica and Doped Silica Membrane for Alcohol Dehydration by Pervaporation. Desalination 148: 19-23.

SUZUKI, T., KOSACKI, I. and ANDERSON, H.U. 2002. Microstructure-electrical conductivity relationships in Nanocrystalline Ceria thin Films. Solid State Ionics 151: 111-121.

WILlARD, M.A., KURIHARA, L.K., CARPENTER, E.E., CALVIN, S. and HARRIS, V.G. 2004. Chemically Prepared Magnetic Nanoparticles. Int. Mat. Rev. 49: 125-170.

YANG, Y., JIN, Y., HE, H., WANG, Q., TU, Y., LU, H. and YE, Z. 2010. Dopant-induced Shape Evolution of Colloidal Nanocrystals: the Case of Zinc Oxide. J. Am. Chem. Soc. 132: 13381-13394.

Received 7 August 2012

Accepted 3 September 2012 